\title{
FATIGUE CRACK GROWTH IN A 7075 AL-ALLOY WITH EVALUATION OF OVERLOADING EFFECTS
}

\begin{abstract}
Measurement of fatigue crack growth (FCG) in an Al 7075-T7351 alloy of a particularly high homogeneity was carried out as a part of the Proficiency Test Programme on fatigue crack growth measurement, organised by General Electric Aviation, USA, in collaboration with the company Exova in France. To pass the test programme successfully, a particular attention was paid to improve and verify DCPD (direct current potential drop) method being used for the crack length measurement. Additionally, an investigation of effects of overloads on fatigue crack growth and retardation was carried out. In the CT specimens used, the difference between actual and calculated crack length at the crack starting point was quite significant, approximately $4.3 \mathrm{~mm}$. However, the difference as a function of crack length was almost constant. Results of FCG rates were very self consistent, likely due to the material homogeneity. Values of the parameters $C$ and $m$ measured at the SVUM a.s. laboratory were evaluated as the third best precise from all the 16 worldwide participating laboratories. Retardation effects of overloads of the magnitudes 2.7-times and 3.0-times of the maximum load in the constant range fatigue loading were significant. The overloads resulted in substantial crack closure effects, which, however, did not occur immediately, but just after further fatigue crack extension, comparable with plastic zone size.
\end{abstract}

Keywords: Fatigue crack growth, overloading, crack closure, 7075 Al-alloy, crack retardation

\section{Introduction}

Al 7075 alloy is a high strength material usually used for highly stressed components in lightweight structures, typically in aircraft fittings, gears and shafts, fuse parts, meter shafts and gears, missile parts, regulating valve parts, worm gears, keys, aircraft, aerospace and defence applications [1]. It can be applied in different heat treatment conditions, but the T7351 temper state is most widely used because of improved stress-corrosion cracking resistance. The content of alloying element (weight \%) is $\mathrm{Cu} 1.2-2, \mathrm{Mg} 2.1-2.9$, Zn $5.1-6.1$ and Cr $0.18-0.28$. Typical mechanical properties are $R_{m}=505 \mathrm{MPa}, R_{p 0.2}=435 \mathrm{MPa}$, elongation at break $13 \%$ and fatigue strength (limit) $150 \mathrm{MPa}$. The T6 or T651 temper state is characteristic by somewhat higher mechanical properties, by $10-15 \%$ and increased fatigue strength by $6-7 \%$, but with a lower ductility and reduced resistance to stress corrosion cracking.

In comparison with an $\mathrm{Al}$ alloy widely used in the past and recently, namely Al 2024, the content of Al 2024 alloying elements was $\mathrm{Cu} 3.8$ - 4.9, Mg $1.2-1.8$ and $\mathrm{Mn} 0.3-0.9$, no $\mathrm{Zn}$ or just less than $0.25 \%$. Mechanical properties and fatigue strength were significantly lower in comparison with $\mathrm{Al} 7075$, just elongation at break was higher. These are the main reasons, why the $\mathrm{Al}$ 7075 type has been recently used more frequently.
A rather problematic property of $\mathrm{Al} 7075$ alloy may be fracture toughness, which vary from $22 \mathrm{MPa} \mathrm{m}^{1 / 2}$ to more than $30 \mathrm{MPa} \mathrm{m}^{1 / 2}$ according to the temper state and test orientation. This may be a problem in structures using Damage Tolerance design philosophy having been recently more and more used in connection with the necessity to reduce total weight of structures and to exploit their potential service life to the maximum extent not only in such industrial branches like aircraft [2], but also gradually in other fields, e.g. railway structures and components [3-5]. Therefore, exact knowledge about fatigue crack growth rates and various affecting factors is a very important basis for an assessment of residual fatigue life of structures and their in-service safety and reliability.

Measurement of fatigue crack growth rates has become recently a standard test, described in detail in different international standards, e.g. [6, 7]. Though this type of test is being offered by numerous laboratories, correct results are conditioned by a good experience and carefulness of the staff, besides exact methodology and experimental facilities. Results generated at different laboratories may not be therefore correct. That is why serious and big manufacturers like e.g. General Electric Aviation, a worldwide manufacturer of aircraft engines, organise so called Proficiency Test Programmes (a kind of Round Robin Tests) of fatigue crack growth measurement. Strength department of SVUM a.s. with accredited laboratory decided to participate in this test. To pass

\footnotetext{
* Ivo Cerny

SVUM a.s., Praha, Czech Republic, E-mail: Ivo.Cerny@seznam.cz
} 
the test programme successfully, a particular attention was paid to improve and verify DCPD (direct current potential drop) method being used for the crack length measurement. The remaining material was then used for an investigation of effects of overloads on fatigue crack growth or retardation. Results of this comprehensive programme are described and discussed in this article.

\section{Experimental programme}

The Al 7075-T7351 alloy acquired for the experimental programme was of a particularly high quality. Since it was a material used for the Proficiency Test Programme, it had particularly homogeneous composition, microstructure, mechanical and fatigue properties. Actual proof stress was $445 \mathrm{MPa}$, somewhat higher than typical average proof stress of this material. The only disadvantage was a very high price, but on the other hand, the characteristics affected reproducibility of experimental measurements very positively.

The fatigue crack growth (FCG) measurement was performed according to the latest issue of the ASTM standard [6] on CT specimens of width $W=75 \mathrm{~mm}$ - Fig. 1. Loading was of a sinusoidal type, load asymmetry $R=0.1$, test frequency $f=11-12 \mathrm{~Hz}$ given by the resonance system of the SCHENCK PVQA fatigue machine.
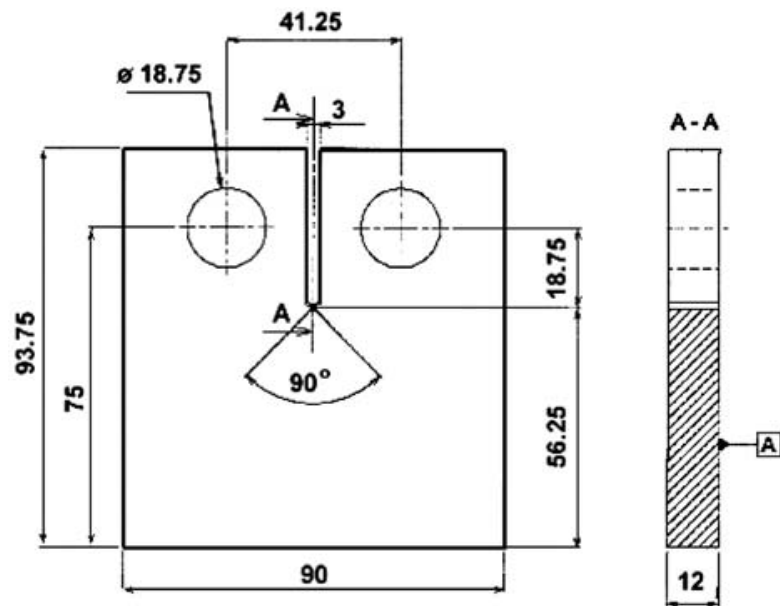

Fig. 1 Scheme and dimensions of CT specimen used for FCG measurement

As already mentioned, particular care was given to improve the precision of the DCPD method and device used. In general, the method corresponded to those described in [8-10]. This method is, however, very suitable for long specimens, where a sufficient length results in a homogeneous direct electric current field in the specimen centre with the growing crack. Unfortunately, in CT specimens being used for FCG measurement very often, the electric current is not sufficiently homogeneous due to insufficient specimen length and presence of attaching pin holes. The modi- fied analytical calibration curve described in [8-10] cannot be therefore directly used, some corrections have to be applied.

The correction function was verified using one of the specimens, where overloading cycles and different load amplitude steps were applied to obtain marking of crack front - Fig. 2. After final braking of the specimen, positions of the crack front markings were exactly evaluated on the microscope. During the measurement, average value of the through thickness crack front, considering inside curvature was evaluated. An example of such the measurement is in Fig. 3.

Effects of overloads on FCG were studied considering just two single overloading cycles and subsequent crack growth at the load amplitude used previously. The overloading cycles were applied at low stress intensity factor ranges $\Delta K$, close to the near-threshold transient area. It was found that FCG rates in the studied material were not sensitive to small overloading cycles - overloading even up to approximately $100 \%$ of the constant load amplitude did not have any measurable effect either on the crack acceleration or retardation. Therefore, quite severe overloading was eventually applied - 2.7-times and 3-times, respectively. Before the overloading and at several intervals after the overloading application, COD was carefully measured. The method of measurement on the back edge of the specimen was used [11] - the clip gauge (high resolution semiconductor clip gauge INOVA) was attached at the centre of the edge opposite to the notch.

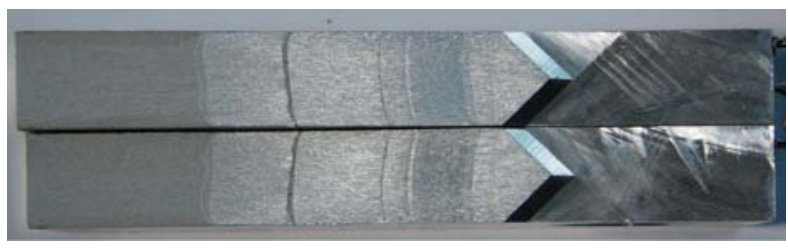

Fig. 2 "Beach" marking of crack front on specimen fracture surface

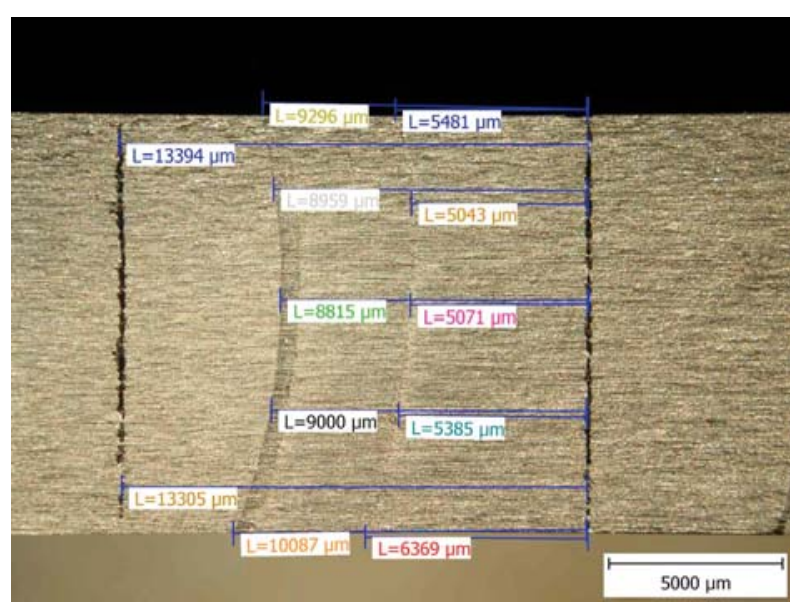

Fig. 3 Example of detailed measurement of crack front considering curvature 


\section{Results and discussion}

\subsection{Correction function of DCPD method}

Results of the optical measurement of the crack front values were compared with crack length values calculated from measured direct potentials according to [8]. Differences between the calculated and optically measured crack lengths $\Delta a$ were determined and a diagram of these differences as a dependence on actual crack length elaborated - Fig. 4.

For the specific case of the specimen type, dimensions, but also material of the specimen - Al-alloy and material of the attaching pins - steel, the difference between actual and calculated crack length at the starting point - actual length approximately $7 \mathrm{~mm}$ was quite significant, approximately $4.3 \mathrm{~mm}$. There was, however, a very advantageous character of this difference as a function of growing crack length: this difference was almost constant, independent on crack length. It can be therefore concluded that the analytical calibration curve can be used for this specimen with just a very simple correction.

It should be noted that the DCPD correction function shown should not be generalised, the DCPD measurement may need a different correction function in other cases, e.g. in combinations of other materials of specimens and pins. The direct current potential field, determined by Laplace equation, is partially affected not only by the attaching holes in the specimens, but also by the material of the pins, because in the holes, there also is some contact between the specimen and the pins.

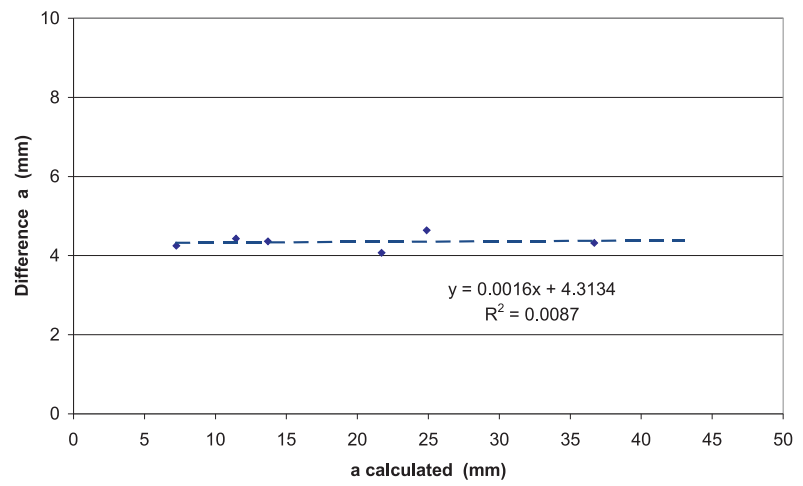

Fig. 4 Differences between actually measured crack length and length calculated from DCPD method

\subsection{Fatigue crack growth in $\mathrm{Al} 7075$ alloy}

Fatigue crack growth in stable - Paris region was evaluated individually for each tested specimen and then a common regression line (power regression) was calculated using methods of mathematical statistics. Note that the very high material homogeneity resulted in very self consistent results - Fig. 5 . The dependencies are almost ideally linear and moreover, differences between individual specimens are negligible either. Parameters $C$ and $m$ of the Paris line were evaluated individually for each specimen and eventually for all the specimens together. The results sent to the company Exova in France, responsible not only for the original distribution of the material, but also for the final evaluation of all results from all participating laboratories.

The final evaluation made by Exova is shown in Figs. 6 and 7 . The precision of the measurement carried out at SVÚM a.s. laboratories is very encouraging: Values of the parameters $C$ and $m$ were evaluated with the third best precision from all the 16 worldwide participating laboratories - Figs. 6 and 7. The reproducibility (repeatability) of the parameter m evaluated at SVUM a.s. was even the best one. Note that all the 16 laboratories have been qualified for accreditation testing for GE Aviation aircraft industry according to specific S-400 quality assurance system, which is very severe. So, the laboratories can be considered as better than average. It is just a confirmation that if a special care and attention is paid to the experimental methodology and measurement precision, such the approach brings good fruits, and eventually the effort is worth it.

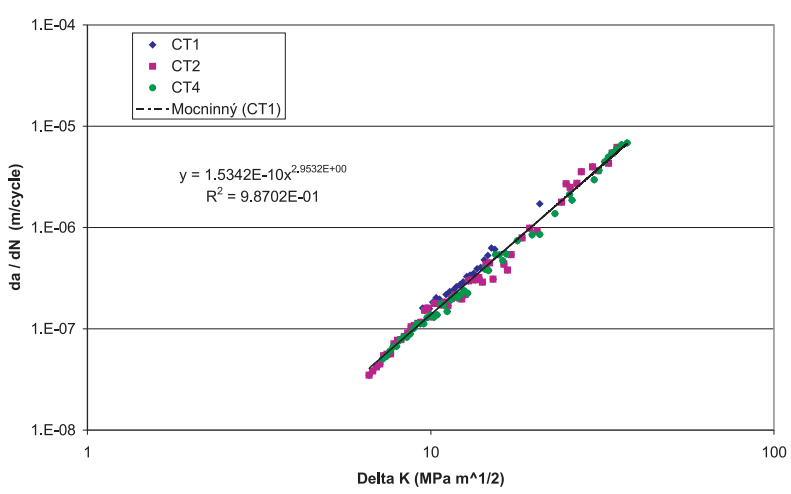

Fig. 5 Fatigue crack growth rates in Al 7075 alloy measured as part of Proficiency Test Programme

\subsection{Effect of overloading cycles on FCG}

Effects of the huge overloads of the magnitudes 2.7-times and 3.0-times of the maximum load in the constant range fatigue loading were significant. The FCG diagram, which includes the overloading cycles and FCG rates after the overloads, is shown in Fig. 8. FCG rate after the first and second overloading was reduced by approximately one order and two orders, respectively. The dashed line in Fig. 8 represents FCG dependence from Fig. 5 - without overloads. It is clear that after the reduction of FCG rates due to the overloading, after some further growth of the crack by increments, approximately comparable with plastic zone size, the values of 


\section{A.G.SPTP}

\section{C coefficient of the Paris law : da/dN $=\mathbf{C}(\Delta K)^{\mathrm{m}}$}
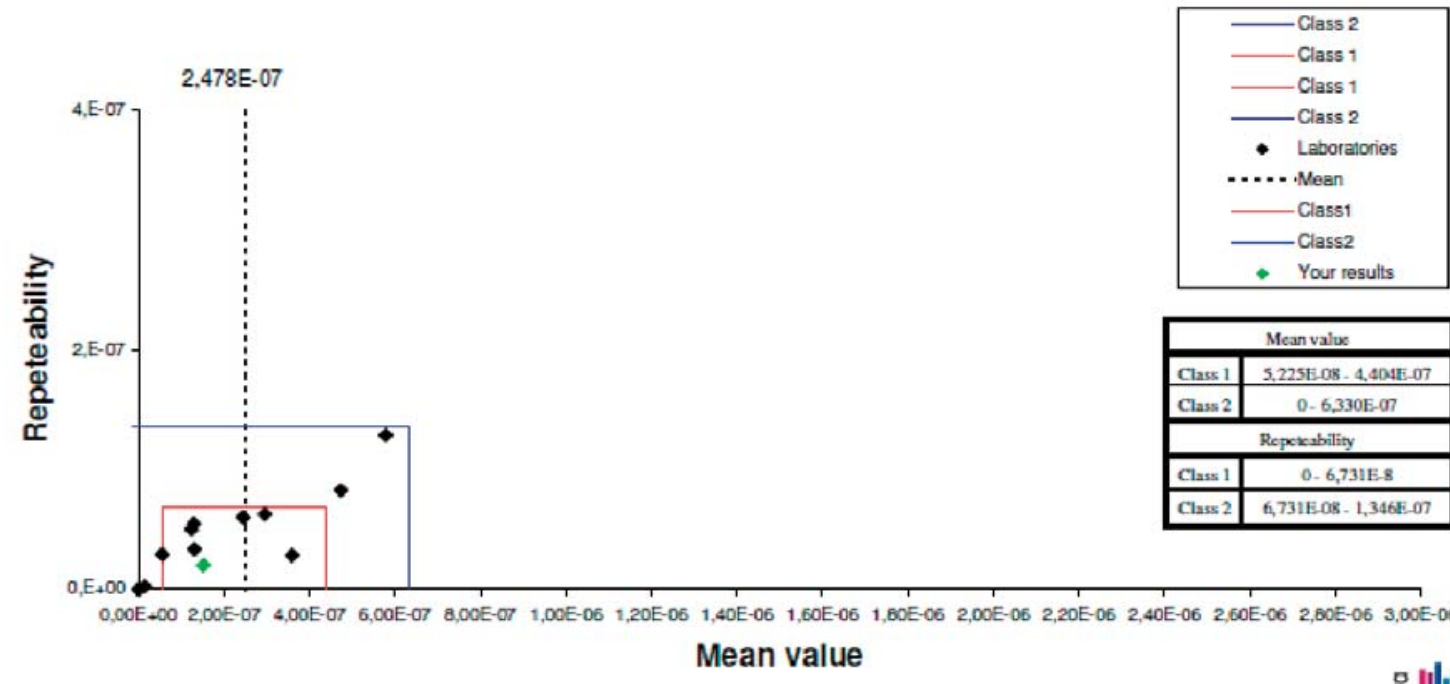

Mean value \begin{tabular}{|l|l|}
\hline Class 1 & $5,225 \mathrm{~L}-0 \mathrm{~s}$ - 4, 4045-07 \\
\hline
\end{tabular} \begin{tabular}{c|c|}
\hline Class 2 & $0-6,330 \mathrm{E}-0 \mathrm{n}$ \\
\hline &
\end{tabular} \begin{tabular}{|r|r}
\hline Class 1 & $0-6,731 \mathrm{E}-8$ \\
\hline
\end{tabular} \begin{tabular}{l|l} 
Class 2 & 6,731E-08 - 1,346E:-07 \\
\hline
\end{tabular}

Fig. 6 Values of coefficient $C$ of Paris dependence evaluated at different worldwide laboratories, result measured at SVÚM a,S, highlighted by green colour

\section{A.G.SPP}

\section{m coefficient of the Paris law $: \mathrm{da} / \mathrm{dN}=\mathrm{C}(\Delta \mathrm{K})^{\mathrm{m}}$}

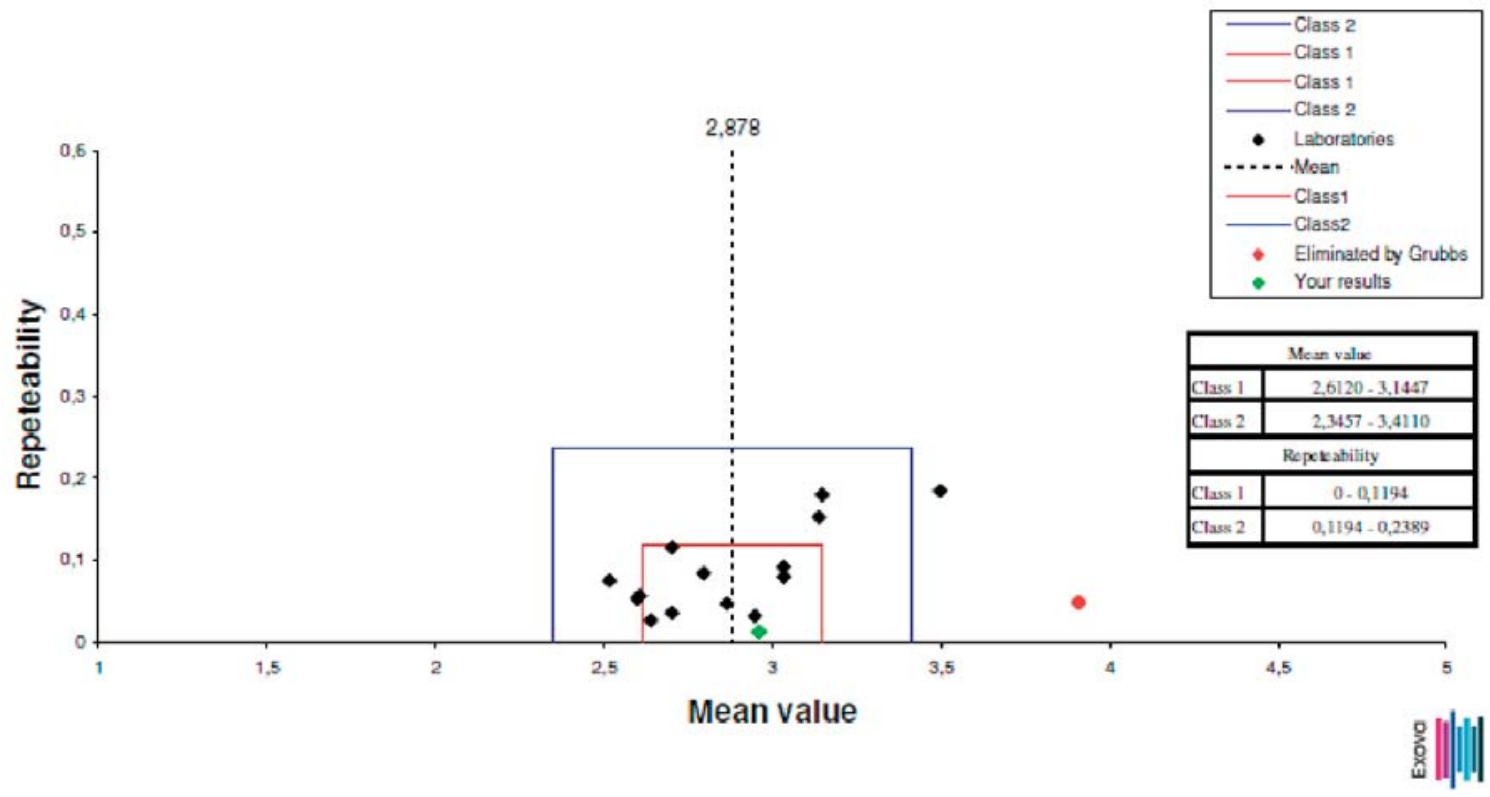

Fig. 7 Values of coefficient $m$ of Paris dependence evaluated at different worldwide laboratories, result measured at SVÚM a.s. highlighted by green colour 


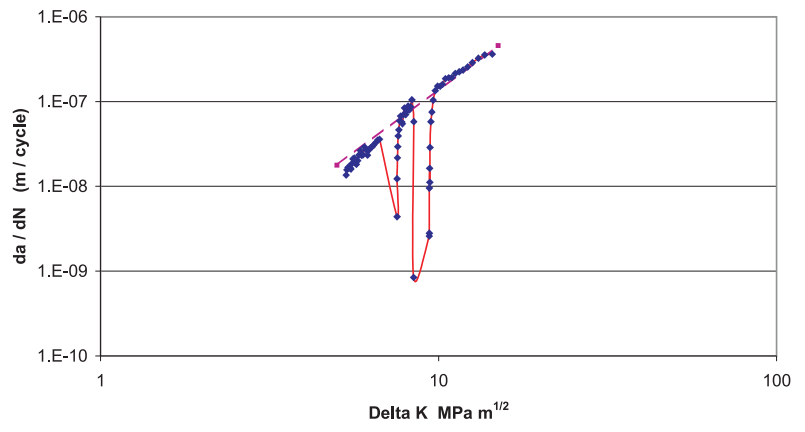

Fig. 8 FCG in Al 7075 alloy including overloading retardation effects

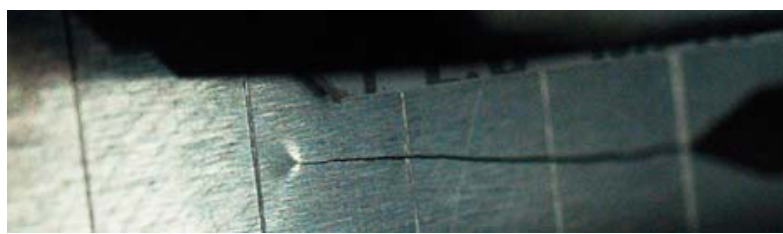

Fig. 9 Plastic zone near crack front during 2.7-times overload, distance between marks being $5 \mathrm{~mm}$

FCG rates gradually, but quite fast rise to their original values. An example of plastic zone after the 2.7-times overload is shown in Fig. 9.

These results are quite comparable with those published in [12], where effects of less severe overloads on FCG rates in the same Al-alloy with a different heat treatment, namely 7075-T651 were investigated besides others. Crack retardation occurred after single overloads, too and crack growth rates also resumed after the crack propagated out of the influencing plastic zone created by the overloads. Similar retardation effects after overloading in a rather different type of Al-alloy, 2124-T351, frequently used particularly in the past but also recently, were described in the literature [13]. In that case like in this work, retardation after a peak overload was observed to extend over the length of the calculated plane strain plastic zone due to the overload.

The evaluation of overloading cycles was completed by measurement of crack closure as a dependence on further crack development. The first group of crack closure measurements was performed already before the first overloading, during the transient period after the last step of load shedding procedure, when FCG was still affected (retarded) by previous, higher load range - approximately the first 10 points in Fig. 8. The second group of measurements was performed after the 3-times overload.

Crack closure forces were evaluated from load/deformation curves recorded during quasi static load cycles, where deformation was measured with clip gauge attached at the specimen edge opposite to the notch ("back edge"), as mentioned in Section 2. Closure force was evaluated as the load value corresponding to the point of declination from the linear part of the curve. An example

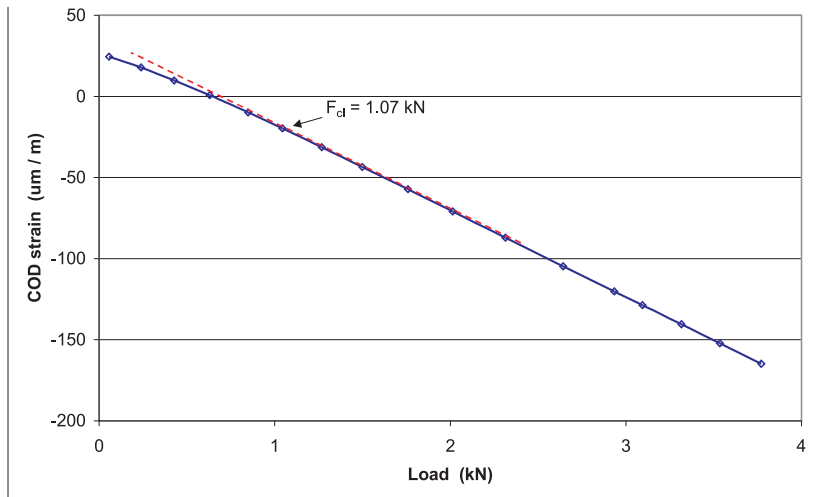

Fig. 10 Example of evaluation of closure force $F_{c l}$ from load/strain curve

is shown in Fig. 10. Note that closure forces evaluated by this method corresponded to plain strain rather than plain stress conditions, as due to fairly big specimen thickness, $12 \mathrm{~mm}$, plain strain conditions predominated near the crack tip, even during the overloading. Crack tip closure forces measured on the specimen surface, at plain stress conditions, would be significantly higher, as shown in [11].

Results of the evaluation of $F_{c l}$ (force corresponding to crack closure) and effective load $F_{\text {eff }}, F_{\text {eff }}=F_{\max }-F_{c l}$ are presented in Figs. 11 and 12. Though the diagrams in Figs. 11 and 12 document different situations, they have quite a similar character. The most important point is some retardation of the crack closure reaction on the overloading. Crack closure did not occur immediately after the application of the overload. As an example, in case of the 3-times overload (Fig. 12), the closure force $\mathrm{Fcl}$ remained constant or even slightly decreased. This result might be in an agreement with recently published, quite surprising numerical analysis of plasticity induced crack closure, where the authors have concluded that such the crack closure actually does not exist at all [14]. Note that other publications dealing with plasticity induced crack closure, even recent, definitely do reckon with this phenomenon and its effect on crack growth rates and retardation [15, 16]. Crack closure, namely closure load $\mathrm{Fcl}$, started to increase just after further crack extension by approximately $0.2-0.3 \mathrm{~mm}$, whereas the maximum closure occurred after $0.7 \mathrm{~mm}$ crack extension after the overload, which is comparable with the end of the plastic zone size. The crack closure returned back to its original value after approximately $1.5 \mathrm{~mm}$ of the total increment after the overload. In case of the final step of load reduction during the load shedding process, crack closure effect remained surprisingly even longer, for more than $2 \mathrm{~mm}$ of the crack increment, though the load range reduction only was $24 \%$.

The evaluated effective load $F_{\text {eff }}$ does not explain the drastic crack retardation - the first two points after the overloads in Fig. 8. It is likely caused by further mechanisms like crack tip blunting or local residual stresses arising in the plastic zone and near it. On the contrary, after the maximum value of crack closure is reached, results of FCG rates are in a good agreement with effective values 


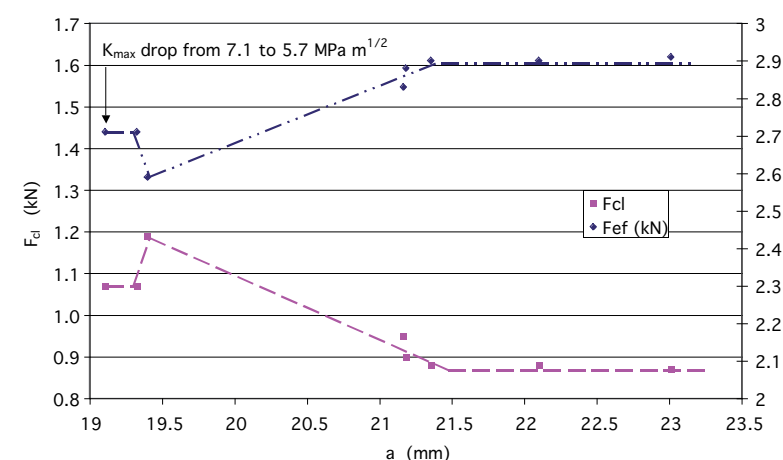

Fig. 11 Closure and effective forces $F_{c l}$ and $F_{\text {eff }}$, respectively, after the last stage of load shedding as a dependence on further crack growth

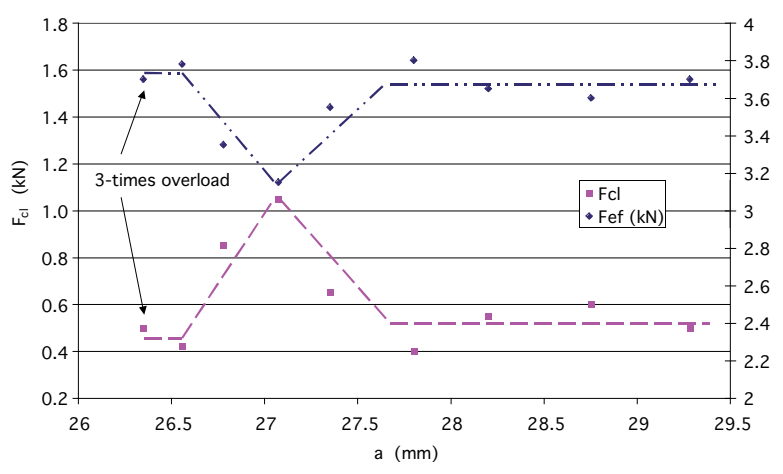

Fig. 12 Closure and effective forces $F_{c l}$ and $F_{\text {eff }}$, respectively, after overloading cycle of stress intensity factor $\Delta K_{\text {eff }}$, like in other recent computational and experimental studies - e.g. [17]. The FCG retardation in the studied case and conditions is caused by the plasticity induced crack closure phenomenon rather than by compressive residual stresses in round bars loaded by rotating bending, described in [18].

\section{Conclusions}

Using an aircraft $\mathrm{Al} 7075$ alloy, the accredited strength laboratory of SVÚM a.s. passed a Proficiency Test Programme on fatigue crack growth measurement, organised by General Electric Aviation, USA, in a collaboration with the company Exova in France. To pass the test programme successfully, a particular attention was paid to improve and verify DCPD (direct current potential drop) method being used for the crack length measurement. Additionally, an investigation of effects of overloads on fatigue crack growth and retardation was carried out. Results of this comprehensive programme can be summarised as follows:

- For the specific case of the specimen type, dimensions and material the difference between actual and calculated crack length at the starting point were quite significant, approximately $4.3 \mathrm{~mm}$. However, the difference as a function of growing crack was almost constant.

- The very high material homogeneity of the Al 7075alloy provided for the Proficiency Test Programme resulted in very self consistent results. The precision of the measurement carried out at SVÚM a.s. was encouraging: Values of the parameters $C$ and $m$ were evaluated with the third best precision from all the 16 worldwide participating laboratories. This result shows that the attention paid to the experimental methodology was worth it.

- Effects of the overloads of the magnitudes 2.7-times and 3.0times of the maximum load in the constant range fatigue loading were significant. The overloads resulted in substantial crack closure effects, which, however, did not occur immediately after the application of the overload, but just after further fatigue crack extension, comparable with the plastic zone size.

\section{Acknowledgements}

The work was carried out under the support of Ministry of Education, Youth and Sports of Czech Republic, grant MSM 2579700001

\section{References}

[1] ASM Aerospace Specification Metals Inc., Aluminum 7075-T73; 7075-T735x, http://asm.matweb.com/search/SpecificMaterial.asp? bassnum=MA7075T73

[2] MOSTA - Modernization of small transport aircraft to increase operation effectiveness and economy. Project FR-TI 2/557 of the programme TIP of the Czech Ministry of Industry and Trade, 2010.

[3] ZERBST, U., SCHODEL, M., BEIER, H. T.: Eng. Fract. Mech., 78, 2011, 5, 793

[4] ZERBST, U., BERETTA, S.: Eng. Fail. Anal., 18, 2011, 2, 534

[5] BERETTA, S., ZERBST, U.: Eng. Fract. Mech., 78, 2011, 5, 713

[6] ASTM E647 - 11. Standard Test Method for Measurement of Fatigue Crack Growth Rates, 2011

[7] ISO 12108:2002. Metallic materials. Fatigue testing. Fatigue crack growth method. 2002

[8] CERNY, I.: Eng. Fract. Mech., 71, 2004, 4-6, 837

[9] CERNY, I: Int. J. Pres. Ves. Pip., 78, 2001, 11-12, 893

[10] CERNY, I.: Procedia Engineering, 10, 2011, 3411 
[11] CERNY, I, REMAR, L., CIPERA, M.: Use of Different Methods of Fatigue Crack Closure Measurement and their Vomparison. Proc. of the $47^{\text {th }}$ Int. Conf. on Experimental Stress Analysis, Eds. Marvalova, B., Petrikova I., Capek, L., Sychrov, 2009, 74

[12] ZHAO, T., ZHANG, J., JIANG, Y.: Int. J. Fatigue, 30, 2008, 7, 1169

[13] ROBIN, C., PELLOUX, R.M.: Mater. Sci. Eng., 44, 1980, 1, 115

[14] TORIBIO, J., KHARIN, V.: Key Eng. Mat., 417-418, 2010, 781

[15] CODRINGTON, J., KOTOUSOV, A., WILDY, S., YING HO, S.: Key Eng. Mat., 417-418, 2010, 201

[16] LI, Y., HE, J., ZHANG, Z.: Key Eng. Mat., 417-418, 2010, 653

[17] SEIFI, R., BAHRAMI R.: Eng. Fail. Anal., 17, 2010, 6, 1475

[18] PURNOWIDODO, A., MAKABE, C.: Eng. Fail. Anal., 2009, 7, 2245 